\title{
"LIQUIDUM NON FRANGIT JEJUNUM": LA POLÉMICA RELIGIOSA EN TORNO AL CHOCOLATE Y SU REFLEJO EN EL ARTE DE LA EDAD MODERNA
}

\author{
Vanesa Quintanar Cabello \\ Universidad de Valladolid
}

\begin{abstract}
Among the foods that arrived in Europe from America at the beginning of the Modern Age, cocoa (Theobroma cacao) was undoubtedly one of those that produced the greatest interest among Europeans who, from the first testimonies, showed an ambivalent posture between fascination and fear towards a product to which all kinds of properties were attributed. One of the most sceptical sectors with cocoa was the Catholic Church, considering that its consumption could go against the rules of fasting. This controversy was the subject of numerous texts and required the intervention of Cardinal Brancaccio to settle it. Based on the aforementioned texts, this article considers how this controversy about the consumption of chocolate and its subsequent abandonment could have been transferred to the world of art. To this end, the main artistic images of chocolate produced in Spain in the seventeenth and eighteenth centuries will be analysed, showing the characteristics and evolution in the presentation of the product and all the elements surrounding its consumption (tableware, consumers, environments...) with the aim of demonstrating the parallel development of the religious controversy and its artistic representation in Spain.
\end{abstract}

Keywords: chocolate; Religion; Catholic Church, Art, Modern Ages.

Resumen: De los alimentos que llegaron a Europa procedentes de América a comienzos de la Edad Moderna, sin duda, el cacao (Theobroma cacao) fue uno de los que mayor interés produjo entre lo europeos que, desde los primeros testimonios, mostraron una postura ambivalente entre la fascinación y el miedo hacia un producto al que se le adjudicaba todo tipo de propiedades. Uno de los sectores más escépticos con este alimento fue la Iglesia, al considerar que su consumo podía ir en contra de las normas del ayuno católico. Esta polémica fue objeto de numerosos textos e hizo necesaria la intervención del cardenal Brancaccio para zanjarla. A partir de los citados textos, el presente artículo plantea cómo esta polémica en torno al consumo del chocolate y su posterior abandono pudo tener su traslación al mundo del arte. Para ello, se analizarán las principales imágenes artísticas del chocolate producidas en España en los siglos XVII y XVIII, mostrando las características y evolución en la presentación del producto y de todos los elementos que rodeaban su consumo (la vajilla, los consumidores, los ambientes ) con el objetivo de demostrar el desarrollo paralelo de la polémica religiosa y de su representación artística en España.

Palabras clave: chocolate; Religión, Iglesia Católica, Arte, Edad Moderna.

Citar como: Quintanar Cabello, V. (2022). "'Liquidum non frangit jejunum': la polémica religiosa en torno al chocolate y su reflejo en el arte de la Edad Moderna". En: Actas del III Congreso Internacional sobre Patrimonio Alimentario y Museos. 25-26 noviembre, 2021, Valencia, España. pp. 171-183. https://doi.org/10.4995/EGEM2021.2021.13337 


\section{Introducción. Primeras impresiones sobre el cacao}

Cuando los españoles llegaron al continente americano, el árbol del cacao (Theobroma cacao) era ya considerado una planta especial que conectaba con la divinidad y cuyos frutos tenían prestigiosos usos, como servir de moneda o como materia prima para elaborar una bebida ritual.

Tal y como señalan José Pardo-Tomás y María Luz López Terrada (1993), las primeras menciones seguras en textos europeos al cacao y sus diferentes usos, incluido el alimenticio, vendrían de la mano de Hernán Cortés y de Pedro Mártir de Anglería. El primero desembarcó en abril de 1519 en las costas de Tabasco y, ya en su primera carta informe al emperador Carlos V, hace mención del cacao, «un fruto como la almendra que ellos venden molido; y tiénenlo en tanto valor que se trata por monedas en toda la tierra y con ella se compran todas las cosas necesarias en los mercados y otras partes» (Cortés, 1886: 94). Por su parte, Pedro Mártir de Anglería no solo hace mención del cacao en sus textos, sino que realiza, además, una de las primeras distinciones entre los diferentes usos que de este se hacía en Mesoamérica. Así, en la quinta de sus Décadas del Nuevo Mundo, redactada entre 1521 y 1523 para el papa Clemente VII, ofrece una distinción entre sus usos como moneda y como bebida e incluye además una expresiva alabanza a sus cualidades (Anglería, 1944: 393).

Sin duda, uno de los elementos que centrarán la atención de estos primeros testimonios serán, sin duda, los efectos sobre sus comensales. Quizás el más polémico de todos ellos lo constituía el aumento de la libido. Uno de los primeros en hacerlo notar es Bernal Díaz del Castillo que, al hablar de las costumbres de Moctezuma en su Verdadera Historia de la Conquista de la Nueva España, alude abiertamente a las propiedades afrodisíacas «de cierta bebida hecha del mismo cacao», que el soberano azteca usaba «para tener acceso con mugeres» (Díaz del Castillo, 1837, Vol. II: 93).

En relación con esto, la capacidad de despertar pasiones es otro de los elementos destacados por el escritor y comerciante italiano Francesco Carletti, que subraya en sus escritos su carácter adictivo, al señalar que «acostumbrándose a ella se vuelve cosa viciosa, y que con dificultad se puede dejar de beber cada mañana o durante el día por la tarde... Es por tanto, una sustancia adictiva» (Carletti, 1976: 61-63).

Cargado de estas y otras connotaciones, como sus efectos vigorizantes o su capacidad para aplacar la sed, los primeros cargamentos llegaron en 1585 a Sevilla procedentes de Veracruz (Harwich, 2018: posición 980) y, en pocos años, se inició un fluido comercio y una intensificación en la explotación de las plantaciones de cacao con el fin de abastecer la demanda a ambos lados del Atlántico. A ello contribuyó la adaptación al gusto europeo y su «hibridación», con el fin de «cruzar la barrera etnocéntrica del gusto y ser aceptado como una bebida normal por parte de los españoles y criollos» (Coe y Coe, 1996: 112-115), fundamentalmente mediante tres estrategias: la adición de ingredientes procedentes de Europa a la receta original, en especial el azúcar, la adición de especias conocidas y su consumo como bebida caliente y no fría como solían hacer los aztecas.

A pesar de este proceso de adaptación, tal y como señala Carmen Simón (2010), durante el siglo XVI y principios del siglo XVII el chocolate se mantiene prácticamente como un secreto disponible solo para la corte española. Los primeros cargamentos de chocolate procedente de América iban a parar directamente a la corte, donde a menudo llegaba como obsequio enviado directamente por los virreyes (Pérez Samper, 1996: 118), lo que explica que la documentación de 
Palacio no registre de manera oficial las primeras remesas (Simón, 1997: 61). A partir de su consumo limitado, se creó todo un ritual de prácticas codificadas, que incluía un amplio despliegue de utensilios para su preparación, servicio y degustación. El hecho de formar parte de esa «red de consumo» se convirtió en sí mismo en un signo de distinción (Fattacciu, 2009: 61).

De esta manera, el chocolate se convirtió en pocos años en una bebida de moda entre las élites, primero españolas y después europeas, que se consumía tanto en ayunas como para la merienda, especialmente entre las mujeres de la aristocracia (Huetz de Lemps, 2011: 784) y que en el siglo XVIII se extendió a otras áreas de Europa y, salvando las distancias en la calidad, a otras capas de la sociedad.

\section{La polémica religiosa frente al consumo de chocolate}

Frente a la pasión mostrada por la nobleza española frente a la bebida americana, su uso (y abuso) suscitó sin embargo un gran escepticismo en otros sectores de la sociedad, especialmente, entre los miembros de la Iglesia Católica. Así, lejos de considerarlo un tema anecdótico, numerosos moralistas se vieron obligados a intervenir por miedo a que su consumo pudiera ir en contra de las normas que sobre el ayuno había establecido la Iglesia católica. La polémica principal se centraba en el hecho de si el chocolate podía consumirse o no durante el periodo de ayuno. Los defensores señalaban que, al fin y al cabo, se trataba de una bebida. Los detractores, sin embargo, argumentaban que sus especiales características saciantes lo convertían en un verdadero alimento y que, por tanto, debía evitarse su consumo.

Uno de sus principales detractores fue, sin duda, el moralista León de Pinelo que, para dar forma a su argumentación, publicó en 1636 su obra Question moral si el chocolate quebranta el ayuno eclesiástico. Como resumen de su postura, baste señalar cómo, con cierta ironía, Pinelo respondía a los que señalaban que el chocolate era una simple bebida:

a este tono pudiera también decir, que la leche, el Atole, las poleadas, i aun unos guevos blandos, una pechuga de ave molida i desatada en caldo, por ser cosas que se beben no eran parte a quebrantar el ayuno (Pinelo, 1636: 113).

En esa misma línea planteará sus argumentos Gaspar Caldera de Heredia en su Tribunal Medicum, Magicum y Politicum (1638), donde señala que el chocolate, debido a su naturaleza, no puede ser consumido antes de comulgar (en Harwich, 2018: Posición 1445).

Otros, sin embargo, plantean serias dudas sobre la validez de estos argumentos y se inclina por su consumo. Este es el caso del teólogo Tomás Hurtado que, en su Chocolate y tabaco, ayuno eclesiastico y natural: si este le quebrante el chocolate, y el tabaco al natural, para la Sagrada Comunión... (1645), que comienza su obra sentenciando que "convienen casi todos, que si uno por enfermedad o flaqueza de estómago bebe en día de ayuno chocolate, no quebrante el precepto porque le bebe por medicina" (Hurtado, 1645: fol 2v.)

Lo irresoluble de esta polémica obligó a que, finalmente, el mismo cardenal Francesco Maria Brancaccio tuviera que dictar sentencia en 1664 y que fue recogida después en su tratado De chocolatis potu diatribe. Según Brancaccio,

El chocolate es una bebida, comparable al vino o a la cerveza, y obedece por ende a la regla establecida por santo Tomás de Aquino según la cual: liquidum non frangit jejunum; con tal, sin embargo, que no se contravenga la ley de la naturaleza que obliga a la templanza en toda cosa y que el chocolate no sea ingerido con la intención de quebrantar el mandamiento de la iglesia (Harwich, 2018: Posición 1454). 
Al margen de las distintas posiciones, lo que esta polémica ponía en evidencia era la necesidad social de aplacar todos aquellos elementos que pudieran constituir una subversión de los principios sociales y religiosos establecidos, incluidos los alimentos procedentes de las colonias. Como señala Irene Fattacciu:

Cacao provoked strong reactions because it was linked to Mesoamerican culture, and its exotic associations with energy, sexuality and abundance made it a potentially subversive element both in the colonies and in Spain (...) This latter quality was the one that aroused polemics and caused sensation, but it was also the source of cacao's success in Europe (Fattacciu, 2009: 61).

Con la llegada del siglo XVIII y la sentencia realizada por Brancaccio, la polémica religiosa y social en torno al chocolate parece desvanecerse: apenas se publican textos sobre este asunto, el tema se trata con un mayor desapego y fundamentalmente desde un punto de vista médico, como las obras del médico Tomás Cortijo Herraiz en su Discurso apologético médico astronómico de 1729 o la de Antonio Lavedán Tratado de los usos, abusos, propiedades y virtudes del tabaco, café, té y el chocolate, de finales del siglo XVIII, centradas en los efectos de su consumo y abuso sobre la salud.

\section{La representación del chocolate en el siglo XVII}

\subsection{Siglo XVII}

Como hemos visto, España fue puerto de entrada y lugar de consumo exclusivo del chocolate durante décadas. Por ello, resulta lógico que la mayor parte de las representaciones del chocolate en el siglo XVII en Europa se concentren en esta zona, aunque fuera, como veremos, de manera implícita.

Porque si algo llama poderosamente la atención es que la imagen del chocolate en el arte español del siglo XVII se realiza generalmente a través de objetos y otros alimentos asociados indisolublemente a su preparación y consumo, pero el chocolate no se muestra de manera explícita, salvo alguna excepción. Son las chocolateras, molinillos, tazas, salvillas o jarras de agua las que sirven para indicarnos que nos encontramos ante los preparativos de una típica merienda de la aristocracia española del siglo XVII. De entre todos estos objetos y por la especial relación geográfica con el producto analizado, merece destacarse la numerosa presencia de cerámica americana, especialmente procedente de la región mexicana de Tonalá, que gozó de buena fama en la época y que a menudo aparece representada en los bodegones donde aparecen servicios de chocolate, aunque también se muestran junto a otros productos y objetos para la preparación y degustación de comida.

Sin lugar a duda, uno de los mejores ejemplos de ocultación del producto e integración de la cerámica mexicana en una escena de servicio de chocolate se encuentra en la obra Bodegón con un cofre de ébano (1652) de Antonio de Pereda

Además de un gran despliegue de elementos, destaca la presencia del cofre que da precisamente título a la obra y que, posiblemente, serviría para mantener guardado con llave el cacao, evitando así posibles hurtos. Y, en el colmo del detallismo, «in Pereda's cozy still-life, the chocolate accompanies not only some colonial Mexican pottery, but also a jar of water -a regular follow-up to the often-bitter brew» (Bendiner, 2004:171) Encontramos por tanto en esta pintura no solo la representación de un servicio de chocolate con todo tipo de detalles, sino el deseo

\footnotetext{
$\overline{1}$ Museo del Hermitage (número de inventario: ГЭ-327).
} 
claro de mostrar con ello el lujo y la distinción a través de objetos (y alimentos) exóticos solo disponibles en aquel momento para las élites.

Sin llegar a ese lujo de detalles, todos los ejemplos localizados muestran al menos un elemento que nos indica que estamos ante los preparativos de una bebida de chocolate. El más evidente es la chocolatera, que encontramos, por ejemplo, en el Bodegón con servicio de chocolate (ca.1640) de Juan de Zurbarán², el Bodegón con caza (ca.1647) de Francisco Barrera³ o en el Bodegón con sandía anónimo ${ }^{4}$, entre otros.

Además de chocolateras, también encontramos en cuadros del siglo XVII español jícaras, como en el anónimo Bodegón con fruta y vajilla ${ }^{5}$; salvillas, como puede apreciarse en Limones, naranjas, taza y rosa (1633) de Francisco de Zurbarán6; infernillos de carbón, como el que aparece en Febrero. Bodegón de invierno (1640) de Francisco Barrera (figura 1)7 o molinillos para conseguir la espuma, como en Bodegón con servicio de chocolate (ca. 1640) de Juan de Zurbarán ${ }^{8}$

Varios de estos elementos también se encuentran en el Bodegón con servicio de chocolate de Juan de Zurbarán del Museo de Besançon que, además, presenta rasgos llamativamente «mundanos» y modernos para la época. Quizás en clara relación con ellos, esta obra destaca por ser el único cuadro español del siglo XVII localizado donde se representa explícitamente el chocolate, que asoma con claridad en la taza. Aunque sin presencia explícita del chocolate, esa modernidad y gusto por los detalles de Juan de Zurbarán se confirma en el ya mencionado Bodegón con servicio de chocolate del Museo de Kiev donde «los objetos (...) pierden la fuerza solemne y monumental que nace del severo aislamiento en que los muestra Francisco, y tienden a agruparse en composiciones complejas, de esquema triangular en profundidad» (Pérez Sánchez, 1983: 77).

Además de los objetos para la preparación y degustación del chocolate que sirven, salvo en el excepcional cuadro de Juan de Zurbarán, para representar indirectamente al chocolate, otro de los elementos que caracteriza su imagen en la pintura española del siglo XVII es el hecho de estar acompañado de otros alimentos. En este sentido, podemos hablar de dos tipos de alimentos.

Por un lado, en los ejemplos localizados se encuentran aquellos alimentos que se consumían asiduamente junto al chocolate, constituyendo así una merienda prototípica de la época. Destacan sobre todos estos alimentos los llamados barquillos de soletilla, que aparecen, entre otros, en Melocotones, pescado, castañas, caja de dulces, molinillo de chocolate y jícara lacada (ca.1635) de Antonio Ponce ${ }^{9}$ o en los ya citados Febrero. Bodegón de invierno de Francisco Barrera y Bodegón con un cofre de ébano de Antonio de Pereda, entre otros. Además de los barquillos, otros bollos y tartas o incluso panes, como los que aparecen en Escena de cocina

\footnotetext{
2 Musée des Beaux-Arts et d'Archéologie de Besançon (número de inventario: 896.1.85).

3 En el mercado anticuario de Madrid en 1995. Mencionado en Jordan W.B. y Cherry P., Spanish Still Life from Velázquez to Goya, 1995: 108.

4 F. Mont, Nueva York (Fuente: Fondazione Zeri).

5 Colección privada (subastado en Asta Sotheby's el 14/01/1994, n. 121).

${ }^{6}$ Norton Simon Museum (número de acceso: F.1972.06.P).

7 Museo Nacional del Prado (número de catálogo: P008213).

8 Museo de Arte Occidental y Oriental de Kiev (número de inventario: 51 ЖK).

9 Colección particular, Barcelona. Citado por Moreno (2015: 820).
} 


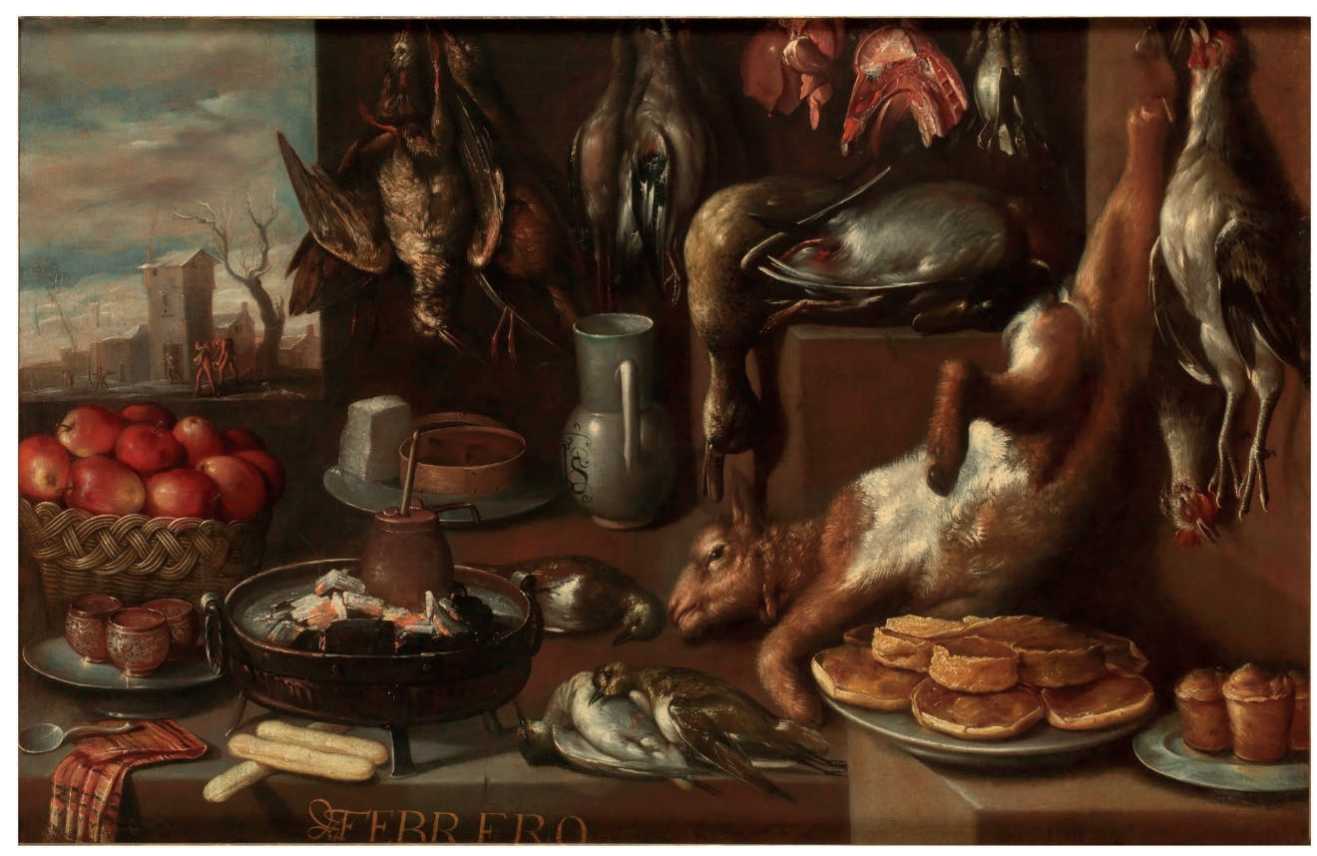

Figura 1. Francisco Barrera. Febrero. Bodegón de invierno. 1640.

Fuente: https://www.museodelprado.es/

(alegoría de la virtud perdida) (ca.1650) de Antonio de Pereda ${ }^{10}$, completan la lista de alimentos ligados directamente al consumo del chocolate.

Pero, además de estos productos, el chocolate (o los preparativos de este) aparece junto a otros alimentos que, a priori, no guardan relación con él. Destaca en este sentido la presencia de frutas: cítricos, como en Limones, naranjas, taza y rosa de Francisco de Zurbarán; manzanas (Febrero. Bodegón de invierno de Francisco Barrera) o frutas de verano, como melocotones (Melocotones, pescado, castañas, caja de dulces, molinillo de chocolate y jícara lacada de Antonio Ponce) o sandías (Bodegón con sandía anónimo). Además de las frutas, encontramos otros alimentos, como la volatería en Bodegón con caza de Francisco Barrera, así como en el Bodegón con servicio de chocolate y pájaros muertos de Francisco Barranco, o piezas de carne, en el mencionado Febrero de Barrera.

Sin ser propiamente un alimento, resulta llamativa la presencia de flores en tres de los ejemplos localizados. Destaca entre ellos uno de los pocos cuadros donde el género no es el bodegón, sino que se trata de una obra de temática religiosa: La joven Virgen (ca. 1632) de Francisco de Zurbarán ${ }^{11}$. Sobre la presencia de los diferentes elementos de este cuadro, incluidas varias florecillas esparcidas por el suelo, Norman Bryson señala:

\footnotetext{
10 Penrhyn Castle, The Douglas Pennant Collection (National Trust) (NT: 1421752).

${ }^{11}$ Metropolitan Museum of Art (número de acceso: 27.137).
} 
La capacidad de ver lo que es insignificante con visión aclarada se presenta como un don espiritual y en la virgen joven los objetos de la naturaleza muerta (flores, libro, tijeras, tapiz, taza de chocolate, cesto de la ropa) son atributos de la santidad, signo de gracia y pureza (Bryson, 2007: 80).

Con una connotación muy diferente, el propio Bryson destaca también la presencia de las flores en otro bodegón de Francisco de Zurbarán, en este caso Limones, naranjas, taza y rosa. En este caso, desde el punto de vista de Bryson, la presencia de flores sería un signo de sensualidad que remite al sentido del olfato, acorde con el aroma del propio chocolate. Según Bryson, de este cuadro destaca «la cuidadosa colocación de la fruta y el ramito de flor de naranjo, e invoca la fragancia de la rosa y el aroma del chocolate en el momento de alzarlos de su sitio para captar su olor» (Bryson, 2007: 76). Una lectura muy diferente a la que hace sobre este bodegón Julián Gállego, para quien todos los elementos del cuadro de Zurbarán no son otra cosa que un homenaje a la Virgen (Gállego, 1984: 202), lo que conectaría con las connotaciones marianas que Bryson apreciaba en el caso de la representación de la virgen niña.

Con mayor seguridad puede dotarse de connotaciones sensuales la delicada flor que descansa junto a las jícaras apiladas en el Bodegón de Juan de Zurbarán del Museo de Besançon, pues, como ya señalamos anteriormente, predomina la sensualidad en todo el cuadro, así como el gusto por lo material y lujoso, una lectura más improbable en el caso de los cuadros de su padre.

Sea cual sea la connotación de las flores, su presencia al lado de alimentos a priori ajenos al chocolate debe entenderse no tanto como una manera de mostrar elementos de una receta, sino como una manera de contextualizar la escena dentro de un ambiente noble. El chocolate, junto a flores, codiciadas piezas de carne, volatería, bollos y dulces, así como una suntuosa vajilla, conforman un «paisaje gastronómico» que en el siglo XVII español solo era posible encontrar en las casas más acomodadas.

Un último elemento a tener en cuenta en la representación del chocolate en la pintura española del siglo XVII es la presencia humana en estas escenas. Sobre este elemento, hay que señalar que tan solo en una escena de las localizadas aparece representada la figura humana: Escena de cocina (alegoría de la virtud perdida), de Antonio de Pereda. Si tenemos en cuenta el título y lo representado en este cuadro, resulta cuando menos significativo que la única presencia humana junto al chocolate o a los instrumentos para su preparación sea en una obra de fuertes connotaciones alegóricas negativas. Así, lo que vemos en la imagen no es otra cosa que una cocina que acusa los excesos del convite que acaba de finalizar. Rodeados de restos de comida y de decenas de utensilios de cocina desparramados por el suelo, la cocinera parece pedir ayuda al soldado, que, mientras la observa, se sirve vino. Tras el caos de la escena y el dramatismo de los personajes se esconde una imagen de fuerte simbolismo en la que Pereda parece advertir de las consecuencias de los excesos humanos y del riesgo que ello supone para la virtud. De entre todos los elementos, tres objetos situados en el suelo junto a la muchacha parecen resumir a la perfección esta idea: el candelero con la vela apagada y truncada, la cerámica rota y, sobre ella, una chocolatera cuya tapa y molinillo se han salido de su sitio con el impacto.

\subsection{Siglo XVIII}

Como vimos en el apartado de introducción, el consumo del chocolate aparece completamente normalizado en la vida de los españoles en el siglo XVIII, aunque sigue siendo fundamentalmente una costumbre cotidiana perteneciente a las clases acomodadas. 
Por lo que respecta al arte, el chocolate mantiene a lo largo del siglo XVIII su presencia en la pintura española, no solo con un número creciente de obras respecto a la anterior centuria, sino también de manera diferente.

La primera gran novedad en su representación dentro de los bodegones dieciochescos españoles es que el chocolate se muestra en muchos de ellos de manera explícita. Lo encontramos en forma de pastillas, por ejemplo, en el famoso Bodegón con servicio de chocolate y bollos (1770) ${ }^{12}$ de Luis Meléndez y en el Bodegón con panes, servicio de chocolate, uvas y melón del mismo autor ${ }^{13}$. Pero, sobre todo, aparece representado líquido y servido (o incluso ya consumido) en las tazas, como en las obras de Juan Bautista Romero, Bodegón de fresas y chocolate (ca. 1775) $)^{14}$ o en Bodegón ${ }^{15}$.

La segunda novedad, en clara relación con la anterior, es la enorme sensualidad que se muestra en la representación del chocolate en este tipo de imágenes. Con llamativa frecuencia encontramos cómo el contenido de la taza parece rebosar y salirse del recipiente, como en los ya mencionados bodegones de Romero. En otros casos, las tazas solo muestran ya los restos de la bebida e incluso aparecen volcadas en la mesa, como en Bodegón de merienda con melero, jarro, chocolatera y dos jícaras de José López Enguídanos ${ }^{16}$, ya de comienzos del siglo XIX.

Estas marcas que denotan su consumo son la prueba indirecta de presencia humana en las escenas, que continúa sin mostrarse explícitamente, con la excepción de La chocolatera de Félix Lorente ${ }^{17}$. Los servicios de chocolate ya no aparecen, pues, como conjuntos que están ahí para ser admirados, sino para ser disfrutados. La rigidez generalizada del siglo anterior da paso a composiciones más dinámicas e incluso, en algunos casos, dominadas por un cierto caos en el que alimentos e instrumentos aparecen representados con escaso decoro y entre los cuales encontramos, por ejemplo, un indolente gato, como en Bodegón con chocolate, frutas y gatos de Juan Pedro Peralta ${ }^{18}$.

En contraste con ese cierto tono desenfadado, otros ejemplos mantienen el recato de la pasada centuria, como en el caso del Bodegón con servicio de chocolate y bollos de Meléndez (figura 2). El contexto, en este caso, podría servir para explicar la formalidad conservadora de su representación. Este cuadro formaba parte de cuarenta y cuatro bodegones pintados entre 1759 y 1774 para el príncipe de Asturias, el futuro Carlos IV, que tenía como objetivo representar en pinturas los productos naturales de España. A pesar de la pretensión de Meléndez de ofrecer una mirada cuasi científica a su representación, los resultados en general distaron mucho de alcanzar dicho objetivo, lo que explicaría que finalmente la serie no fuera a parar al Real Gabinete de Historia Natural como pretendía Meléndez.

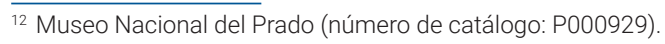

${ }^{13}$ Colección August Oetker.

${ }^{14}$ North Carolina Museum of Art de Raleigh (número de objeto: G.52.9.184).

${ }^{15}$ Museo de Bellas Artes de Bilbao (número de inventario: 82/428).

${ }^{16}$ Colección particular, Colombia. Expuesto en la exposición «ln the presence of things: Four centuries of European Still-life Painting», Lisboa, Calouste Gulbenkian Foundation. 12 febrero-2 mayo 2010.

17 Colección Juan Abelló.

${ }^{18}$ Real Academia de Bellas Artes de San Fernando (número de inventario: 1398).
} 


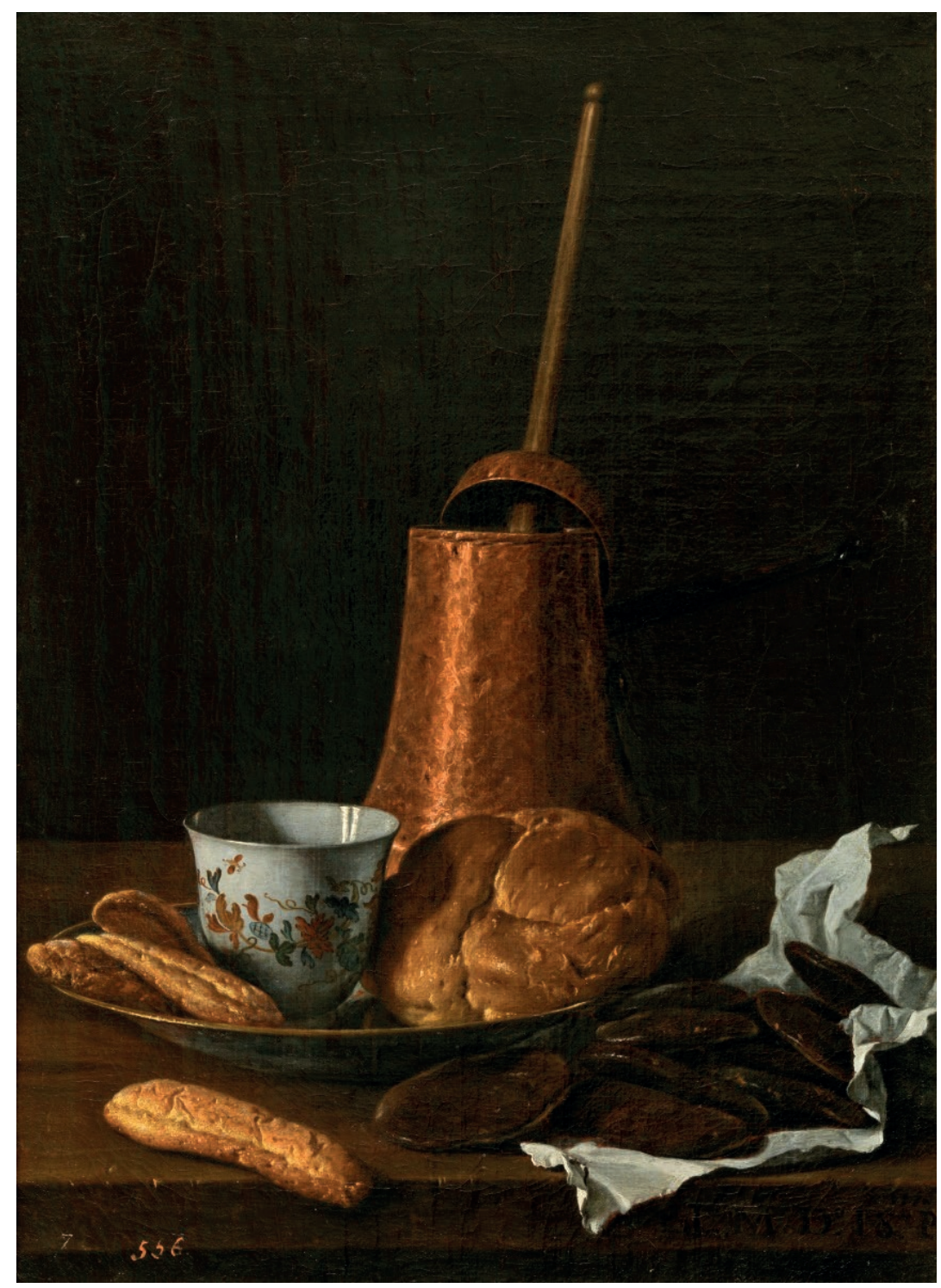

Figura 2. Luis Meléndez. Bodegón con servicio de chocolate y bollos. 1770 Fuente: https://www.museodelprado.es/

A diferencia de este carácter especialmente distinguido y preciso, este mismo autor presenta el chocolate en un tono más distendido y más cercano a las formas de sus coetáneos en Bodegón con panes, servicio de chocolate, uvas y melón, donde encontramos una «salva con pie que sostiene en su centro una taza mejicana de Guadalajara, y alrededor de ellas unas jícaras, también de Guadalajara (Méjico), muy próximas a la labor de Salvatierra de los Barros (Badajoz)» (Gutiérrez, 1983: 165). Además, la disposición tanto de la vajilla como de los bollos 
y los pequeños paquetes en los que solían guardarse las especias reflejan un tono mucho más relajado que en el anterior bodegón.

Junto a la presencia explícita del chocolate y una mayor sensualidad en la presentación de este producto, que denota además una innegable presencia humana en la escena, pero en clara relación con ellos, hay que destacar como rasgo de su imagen en el siglo XVIII español que el carácter de distinción y protocolo de estas escenas no es tan marcado como en el siglo anterior. Si bien encontramos elementos de las vajillas que solamente estarían al alcance de personas adineradas, especialmente en las obras de Romero que «expresan un mundo de refinamiento y exquisitez, de sedas, encajes y porcelanas, un tanto singular en nuestra pintura» (Pérez Sánchez, 1983: 107), en general, parece que la representación del chocolate huye de la ostentación del siglo XVII. Los exquisitos objetos de Pereda o las despensas rebosantes de Barrera dan paso a contextos más sencillos o desenfadados, con un mobiliario más discreto o que incluso desaparece, como en el Bodegón de fresas y chocolate de Romero, donde el mantel se ha colocado directamente sobre el suelo en lo que parece ser una «merienda veraniega al aire libre» conformada por «un postre de fresas, azúcar, chocolate, bizcochos y pan, sobre un limpísimo mantel blanco con encajes». Todos estos elementos son «presentados como si estuvieran destinados a una sola persona: el espectador» (Jordan y Cherry, 1995: 171).

Pero los bodegones no fueron las únicas manifestaciones artísticas que a lo largo del siglo XVIII sirvieron para representar la difusión y el consumo del chocolate en España. Junto a estas escenas, las artes decorativas fueron un testigo especialmente valioso, pues en ellas el chocolate no es mostrado solo como un delicioso dulce, sino como el punto culminante de un evento social, el del «refresco».

Quizás esta importancia social explica su representación en las artes decorativas españolas, especialmente en las cocinas de las casas más acomodadas, concebidas en aquel momento como el centro de la vida en el hogar, donde no solo se cocinaba, sino que servían de punto de encuentro para veladas y tertulias. Esta transformación de un espacio íntimo en un espacio social explica la moda de decorar las cocinas nobles con azulejos procedentes de las fábricas de Valencia, por lo que se conocieron popularmente con el nombre de «cocinas valencianas», y en los que el chocolate ocupaba un lugar principal y exclusivo entre las bebidas estimulantes. Además del producto, y a diferencia de su representación en los bodegones, la presencia humana no solo es patente en este tipo de representaciones, sino que adquiere un papel absolutamente principal, como muestra la cocina valenciana presente en el Museo Nacional de Artes Decorativas de Madrid ${ }^{19}$ o los azulejos que se conservan en el Museo Nacional de Cerámica y Artes Suntuarias González Martí20.

\section{Conclusiones}

Desde los primeros contactos con el cacao, los europeos fueron conscientes de que estaban ante un producto especial. Como vimos al inicio de este artículo el chocolate se convirtió en pocas décadas en un alimento lleno de connotaciones, entre las que pronto sobresalieron sus supuestas cualidades afrodisíacas y su consumo compulsivo.

\footnotetext{
${ }_{19}$ Museo Nacional de Artes Decorativas de Madrid (número de inventario: CE05135).

${ }^{20}$ Museo Nacional de Cerámica y Artes Suntuarias González Martí (número de inventario: CE1/00804).
} 
Ante ello, como vimos, numerosos teólogos, especialmente en España e Italia, cuestionaron si el consumo del chocolate podía suponer un perjuicio muy grave para los fieles que, considerándolo interesadamente o de buena fe una simple bebida, podían estar incurriendo en el grave pecado de quebrantar el ayuno cristiano. Este largo y complejo debate, en el que se invocaron a las grandes figuras de la cristiandad, confirmaba que los prejuicios que el chocolate había adquirido desde su conocimiento no solo no habían desaparecido, sino que se habían hecho más palpables durante su expansión en Europa, una vez constatada que la pasión por este producto no era solo una cuestión bárbara, ni siquiera algo propio de europeos que, asentados en aquellas tierras, habían corrompido su alma, sino algo que amenazaba con convertirse en un problema generalizado.

Ante este problema, cabe preguntarse si el arte fue sensible y lo reflejó de alguna manera. A la luz de los ejemplos localizados puede considerarse que sí.

En primer lugar, frente al enorme éxito del producto y si comparamos la representación artística del chocolate con otros productos americanos también exitosos, como el pavo ${ }^{21}$, destaca la presencia relativamente escasa del cacao en el arte europeo de la Edad Moderna, tanto de la planta (de la que no se ha consignado ni una sola representación artística) como del chocolate. A diferencia de otros productos, como el pavo o el maíz, que son introducidos rápidamente en el arte europeo de aquella época, la representación del chocolate es mucho más tardía y no hace su aparición hasta el siglo XVII. Ausente en el arte del siglo XVI, pues, el chocolate permanece aún una centuria más con una representación muy restringida y podría decirse que eminentemente española. Dos razones, ya apuntadas a lo largo del texto, podrían explicar esta escasa presencia.

Por un lado, el propio contexto de la llegada y difusión del chocolate. Como ya quedó mostrado, el cacao y el producto derivado del mismo, el chocolate fue consumido durante muchos años casi exclusivamente por la nobleza española. Este carácter casi «clandestino» podría explicar su ausencia en el campo de la representación a lo largo del siglo XVI y su discreta representación en el siglo XVII.

Pero, junto a las razones históricas, consideramos que un elemento que podría resultar clave para el «ocultamiento» artístico del chocolate podría encontrarse en la polémica religiosa que generaba su consumo. Como ya quedó reflejado, el encaje del chocolate en la dieta de los europeos, tanto de aquellos que vivían en territorio americano como de aquellos que lo consumían en Europa, resultó problemático, pues su uso (y abuso) podía entrar en conflicto con los principios católicos, incitando a sus fieles a incurrir en graves pecados como el de la gula, la lujuria o el quebrantamiento del ayuno. Se trataba, pues, de un alimento paradójico que, por un lado, despertaba fuertes pasiones y, por otro, era considerado altamente peligroso para la integridad espiritual de sus consumidores y también para su salud, como advirtieron los médicos desde los primeros contactos con este alimento.

Ambas razones parecen argumentos de peso para que los artistas y las personas que encargaban las obras prefirieran no hacer un excesivo alarde del consumo de este polémico producto. Estos mismos argumentos pueden ayudarnos a comprender la peculiar representación de este producto en el siglo XVII. Salvo la excepción ya comentada del Bodegón con servicio de chocolate de Juan de Zurbarán, la abrumadora mayoría de las representaciones localizadas de ese siglo no muestra el producto en sí. Se trata, en prácticamente todos los casos, de lo que

\footnotetext{
${ }^{21}$ Ver Quintanar Cabello, Vanesa, La llegada y adaptación de productos americanos en Europa y su representación en el arte europeo de la Edad Moderna [tesis doctoral], 2021.
} 
podríamos denominar una representación metonímica en la que el continente sustituye al contenido. Chocolateras, molinillos o jícaras nos dan pistas sobre su contenido, pero el chocolate no se hace explícito.

Además de su representación metonímica, la ausencia directa o indirecta de presencia humana en las obras del siglo XVII incide también en una imagen de clandestinidad y secreto de este producto. Como vimos en el apartado correspondiente, tan solo un cuadro, Escena de cocina (alegoría de la virtud perdida) de Antonio de Pereda, nos muestra figuras humanas y, de manera muy significativa, se trata de una obra que nos habla de las fatales consecuencias de la falta de virtud y decoro.

Por contraste frente a estas características estables a lo largo del siglo XVII, destaca el significativo cambio que su representación experimenta a lo largo de la centuria siguiente, especialmente en la segunda mitad del siglo XVIII.

En primer lugar, y en contraste con la representación metonímica generalizada que observamos en el siglo XVII, los cuadros de la siguiente centuria sí muestran el producto mismo de manera explícita y variada. Lo vemos en forma de pastillas (Bodegón con servicio de chocolate y bollos de Luis Meléndez) o ya preparado como bebida (Bodegón de fresas y chocolate de Juan Bautista Romero).

La segunda diferencia importante entre la representación del chocolate en ambos siglos es la presencia directa o indirecta de personas en el siglo XVIII. En el caso de España, los cuadros siguen sin mostrar explícitamente las figuras, con la excepción de La chocolatera de Félix Lorente, pero sí lo hacen de manera indirecta, al mostrar dulces a medio comer, tazas vacías o bizcochos sumergidos en las tazas a punto de ser degustados. En contraste con la pintura, las artes decorativas españolas, como las cocinas valencianas ya comentadas, sí muestran a los comensales.

Lógicamente, detrás de este notable cambio en la representación podemos deducir un cambio de mentalidad general y respecto al consumo del chocolate en particular. A lo largo del siglo XVIII la polémica en torno a los perjuicios espirituales del chocolate queda completamente abandonada y sus comensales no parecen tener que mortificarse por su consumo. Además de ello, la pujanza económica y social de la clase burguesa, así como el paulatino predominio de una mentalidad que valoraba y fomentaba una actitud más sensual hacia la vida, con un creciente valor del ocio y las actividades que fomentasen la sociabilidad, ayudaron no solo a que el chocolate pudiera ser degustado y valorado sin prejuicios, sino a que se convirtiera en un verdadero ritual a través del cual las clases acomodadas encontraban una excusa cotidiana para sociabilizarse. Otro rasgo de esta mentalidad era también romper el rígido protocolo alimentario dominante en siglos anteriores, lo que explicaría que el chocolate sea representado en el siglo XVIII en contextos mucho más relajados e informales.

\section{Referencias}

BENDINER, K. (2004). Food in painting: from the Renaissance to the present. Londres: Reaktion Books.

BRANCACCIO, F. M. (1664). De chocolatis potu diatribe. Romae: per Zachariam Dominicum Acsamitek à Kronenfeld, Vetero Pragensem,

BRYSON, N. (2007). Volver a mirar. Cuatro ensayos sobre la pintura de naturalezas muertas. Madrid: Alianza. 
CARLETTI, F. (1976), Razonamientos de mi viaje alrededor del mundo (1594-1606). México: UNAM.

CHERRY, P. (1999). Arte y Naturaleza. El Bodegón Español en el Siglo de Oro. Madrid: Fundación de Apoyo a la Historia del Arte Hispánico.

COE, S. y COE, M. (1996). The true History of Chocolate. Londres: Thames and Hudson.

DÍAZ DEL CASTILLO, B. (1837). Historia verdadera de la conquista de la Nueva España. París: Librería de Rosa.

FATTACCIU, I. (2009).I "Cacao: From an exotic curiosity to a Spanish commodity. The diffusion of new patterns of consumption in eighteenth-century Spain". En: Food and History. Revue de I'Institut Européen d'Histoire de l'Alimentation, 7(1), 53-78, https://doi.org/10.1484/J.FOOD.1.100635.

GÁLLEGO, J. (1984). Visión y símbolos en la pintura española del Siglo de Oro. Madrid: Cátedra.

HARWICH, N. (2018). Historia del chocolate. Barcelona: Pensódromo 21.

HUETZ DE LEMPS, A. (2011). "Bebidas coloniales y el auge del azúcar". En: Flandrin, J.L. y Montanari, M., Historia de la Alimentación. Gijón: Trea, pp. 781-796.

HURTADO, T. (1645). Chocolate y tabaco, ayuno eclesiastico y natural: si este le quebrante el chocolate, y el tabaco al natural, para la Sagrada Comunión... Madrid: por Francisco García.

JORDAN, W. B. y CHERRY, P. (1995). El bodegón español de Velázquez a Goya. Madrid: El Viso.

LAVEDÁN, A. (1796). Tratado de los usos, abusos, propiedades y virtudes del tabaco, café, té y chocolate. Madrid: En la Imprenta Real.

LEÓN PINELO, A. de (1636). Question moral: si el chocolate quebranta el ayuno eclesiastico: tratase de otras bebidas i confecciones que vsan en varias provincias. Madrid: Por la viuda de Iuan Gonçalez.

MARTIRE D'ANGHIERA, P. (1944). Décadas del nuevo mundo. Buenos Aires: Editorial Bajel.

MORENO, J. (2015). La naturaleza de Indias en la plástica de la Edad Moderna [Tesis Doctoral]. Málaga: Universidad de Málaga.

PARDO-TOMÁS, J. y LÓPEZ TERRADA, M.L. (1993). "Las primeras noticias sobre plantas americanas en las relaciones de viajes y Crónicas de Indias (1493-1553)". Valencia: Cuadernos Valencianos de Historia de la Medicina y de la Ciencia, 40, CSIC-UV - Instituto de Historia de la Medicina y de la Ciencia López Piñero (IHMC).

PÉREZ SAMPER, M. A. (1996). "La integración de los productos americanos en los sistemas alimentarios mediterráneos". En: XIV Jornades d'Estudis Històrics locals. La Mediterrània, àrea de convergència de sistemes alimentaris (segles V-XVIII). Palma: Institut d'Estudis Baleàrics. Govern Balear, Conselleria d’Educació, Cultura i Esports: 89-148.

PÉREZ SAMPER, M. A. (2019). Comer y beber: Una historia de la alimentación en España. Madrid: Cátedra.

PÉREZ SÁNCHEZ, A. E. (1983. Pintura española de bodegones y floreros de 1600 a Goya. Madrid: Museo del Prado y Ministerio de Cultura.

SIMÓN PALMER, M. C. (2010). "El impacto del Nuevo Mundo en los fogones españoles". En: Oltreoceano. Rivista sulle migrazioni, 4, pp. 51-63. https://doi.org/10.1400/197594. 